\title{
Development of an Extended Enterprise Performance Measurement
}

\section{System}

\author{
Paul Folan and Jim Browne
}

Computer Integrated Manufacturing Research Unit (CIMRU), National University of Ireland, Galway, Ireland

Tel.: +353-91-750-414;

Fax: +353-91-562-894.

paul.folan@nuigalway.ie 


\title{
Development of an Extended Enterprise Performance Measurement
}

\section{System}

\begin{abstract}
Discusses the development of a Performance Measurement system specifically designed for the requirements of the Extended Enterprise, via two Performance Measurement frameworks: the structural Extended Enterprise Balanced Scorecard; and the procedural framework for the selection and implementation of measures. The Extended Enterprise Balanced Scorecard offers a four-perspective framework, implementable at each node, that provides a generic structure for the management of performance measures in the Extended Enterprise; while the procedural framework operates at both the local and holistic levels, to provide a step-by-step generic process towards performance measure selection and implementation. When combined, the two frameworks produce the basic Extended Enterprise Performance Measurement system, which was subsequently tested at a first-tier supplier in the European automotive industry. The characteristics of the Extended Enterprise are taken as a given starting point, and the paper concludes by pointing out the need for Extended Enterprise performance management to balance the developments outlined here.
\end{abstract}

Keywords: Extended Enterprise, Performance Measurement, Intra-organisational Performance Measurement, Inter-organisational Performance Measurement, Balanced Scorecard 


\section{Introduction}

The concept of performance, as it is measured and evaluated, is undergoing a transformation in modern business organisations. Globalisation, environmental issues and radical business and organisational structures have brought significant pressures to bear upon companies, who, in an attempt to address these pressures, are forming enterprise networks that work together across the value chain in order to meet more complex customer needs (Browne 1995). The Extended Enterprise (EE) is a formation of closer co-ordination in the design, development, costing and the co-ordination of the respective manufacturing schedules of co-operating independent manufacturing enterprises and related suppliers (Jagdev and Browne 1998); and is the consequent result of a move away from the traditional view of manufacturing companies with clear boundaries, limited relationships with other companies and a focus on internal efficiency and effectiveness only (Browne and Zhang 1999).

Performance Measurement (PM) has also begun to evolve to combat these new organisational realities, as the external environment is becoming identified as the next frontier of PM. In the current literature upon PM, the focus seems to be upon developing PM recommendations into PM frameworks, which, in turn, are to be developed into PM systems. This process is carried out upon an intra-organisational basis, with no analysis of the impact of this PM developmental process upon the external environment - in particular, upon the inter-organisational environment, where other EE nodes lie, such as suppliers and customers. While it may be argued that the PM system that any organisation puts into effect is solely their own business, the concept of PM is changing in the surrounding value chain: increasingly organisations are being asked (and in some cases forced) to accept performance measures from their supply chain partners that they have no 
immediate interest in. The concept of internal PM existing as a stand-alone concept at each EE node is becoming defunct; isolated internally-oriented PM systems existing at separate nodes in the EE make it difficult for PM information to flow unimpeded throughout the value chain to where it is required.

The situation is being exacerbated by the relative absence of research upon inter-organisational PM. Whilst, by the late nineties of the last century and the early years of this century, researchers had laid down numbers of ever more complex PM recommendations, frameworks and systems that attempted to address the complicated nature of intra-organisational PM in a holistic manner; complimentary approaches towards inter-organisational PM are in danger of becoming out of touch with the modern propensity, on the part of organisations, to form enterprise networks such as the EE and the Virtual Enterprise. In the coming years, therefore, there is expected to be a significant increase in inter-organisational PM developments - such as supply chain PM and, more particularly, Extended Enterprise PM.

The purpose of this paper is to help clarify this vision of PM at the EE level, by offering the basic requirements for an Extended Enterprise Performance Measurement system (EE PM system). In the following section, the reader's knowledge of intra-organisational PM is assumed, and the focus is upon the PM literature at the inter-organisational level, in particular the literature upon supply chain and EE PM initiatives. The paper's research methodology is then recounted, followed by the specifications for the EE PM system: the EE Balanced Scorecard, and the procedural frameworks. A case study is then provided and the paper is completed with a brief discussion upon the preceding. 


\section{Inter-organisational Performance Measurement}

Most of the current inter-organisational PM literature concerns itself with supply chain PM: tools and techniques that attempt to extend the discussion beyond this domain are rare. A supply chain PM system focuses upon what are termed by Brewer and Speh (2000) as traditional logistics performance measures (i.e. measures such as order fill rates, error rates, inventory costs, delivery time etc.). By focusing almost completely upon the logistics control system, supply chain PM cannot answer a number of wider-ranging, more holistic questions - for example: How effectively are the firms in the supply chain interacting? How does this supply chain fare compared to competing supply chains? How flexible is the entire supply chain in responding to requests for customised packages, orders and products? To what extent are decisions within the supply chain motivated by power rather than by mutual trust? (Brewer and Speh 2000). These questions are tackled by an Extended Enterprise PM system, which, in effect, incorporates the structural aspects of the supply chain PM system and adds a number of non-logistic perspectives to its measurement arena (for example: internal process measures, intangible measures, measures of financial performance etc.). The supply chain PM system maintains a more traditional armslength relationship with suppliers and customers by requesting data only upon issues of immediate concern from the logistics functions of participating companies. The Extended Enterprise PM system may theoretically present data from all aspects of the participating companies' functions. However developing an Extended Enterprise PM system also requires the development of a robust conceptual supply chain PM framework; thus the two concepts are integral to each other. 
A performance measurement framework assists in the process of performance measurement system building, by clarifying performance measurement boundaries, specifying performance measurement dimensions or views and may also provide initial intuitions into relationships among the performance measurement dimensions (Rouse and Putterill 2003). A number of frameworks specifically designed for the inter-organisational environment have been developed, which are outlined in table 1 . Two types may be envisaged here: the structural framework (i.e. a framework specifying a typology for performance measure management); and the procedural framework (i.e. a step-by-step process for developing performance measures from strategy). When combined, the structural and procedural frameworks produce the basic PM system. Table 1 suggests that the rate of development of frameworks of a structural nature is outpacing those of a procedural nature; this may be explained by the difficult qualitative nature of the problem of formulating basic procedures between companies in the supply chain and EE formations. A number of these frameworks may be seen as extensions of well-established intra-organisational thinking (for example, Brewer and Speh 2000, Bullinger et al. 2002); in particular of the Balanced Scorecard (Kaplan and Norton 1992) concept - probably owing to its advocating a "balanced" set of measures, which, in terms of inter-organisational PM, means a balance of internally-oriented measures against externally-oriented measures.

\section{Insert Table 1 here}

Beamon (1998) concludes that it is unlikely that a single performance measure will be adequate for an entire supply chain, and that a system of performance measures is required for accurate measurement of supply chain systems. Holmberg (2000) has suggested that a lack of systems thinking has plagued supply chain PM system design and development: he suggests that measurement activities in the supply chain should not be managed as one system, but as several independent, fragmented, firm-sized systems that are ultimately managed, upon the supply chain 
level, through the co-ordination of information exchange. This postulation is upheld by the research of Blackhouse and Burns (1999) who emphasise that communication methods to ensure measure visibility at the level of the EE requires further investigation; while Bititci et al. (2003) stipulate that the flow of individual EE node performance management information (such as performance objectives and targets) via a specialised meta manage process should be considered. Kleijnen and Smits (2003), using the Balanced Scorecard approach, postulate that since each company is an economic - and legal - entity, each should have its own scorecard, while communication and co-ordination within the supply chain should be applied to overcome the obstacles created by this independent scorecard development process.

\section{Research Methodology}

The proposed EE PM frameworks that follow were designed deductively based upon the previous research, and from the empirical evidence of a test case EE in the automotive industry. The EE provided empirical evidence of the need for a framework that is competent enough to work at two distinct levels: the holistic EE level; and the individual, EE node, level. Further, the requirements of the EE suggested the need for various levels of accuracy from the EE PM system, in terms of the aggregation of measures; as well as a focus upon the need to overcome communication problems encountered by individual EE nodes in the EE. The combined frameworks were subsequently applied to a first-tier supplier in the same industry as a case study of the EE PM system functionality; this case study was implemented by the author in consultation with the supplier, who committed significant senior manager support to the project. 
In the following sections, the development of two distinct performance measurement frameworks - of a structural and procedural nature - is given, which, when combined, produce the basic EE PM system. The core of the solution lies in the development of a structural EE Balanced Scorecard, and a procedural framework that outlines the process towards the selection and implementation of performance measures, to enable the development of a system of measures that are of relevance at both the intra-organisational and inter-organisational levels. A number of performance management tools associated with the structural and procedural frameworks have also been developed, but these lie outside the immediate scope of this paper. One heavily referred-to management tool, in the following sections, is the performance measure template list: whilst this is too bulky to provide, it is sufficient to say that it consists of approximately 120 performance measures, mainly of a non-financial type, arranged according to seven macro measures of performance: cost, time, quality, flexibility, precision, innovation and environment; at three perspective levels: supplier, internal and customer; and replete with formulas for calculation purposes. Facilities have been put in place to ensure that this template list maintains its currency.

A dashboard solution has been developed to tackle EE communication issues. The dashboard represents a standardised, single point of interaction - that is robust, flexible, and user-friendly for each EE node. By taking advantage of the relatively inexpensive requirements for setting-up an Intranet focused upon EE PM, for each EE node, the dashboard seamlessly connects the EE by means of a generic Extranet, which connects the EE PM Intranets at individual nodes. The dashboard consists of flexible web-based software technology that provides extensibility to allow for future incorporations and modifications. 


\section{Extended Enterprise Balanced Scorecard}

The development of a structural EE PM framework that captures the relevant measurement sectors and puts them into perspective, has been developed by examining an individual company (company $\mathrm{X}$ ) at any tier in the EE. We can define four measurement perspectives for company $\mathrm{X}$ : internal-perspective - located inside the four walls of the company; supplier-perspective located at the interface of the company and its respective suppliers; customer-perspective located at the interface of the company and its respective customers; and the Extended Enterprise-perspective (EE-perspective) - the holistic system. These perspectives may be transposed into the EE Balanced Scorecard framework depicted in figure 1; this framework is applicable for each node of the EE. The framework is 'balanced' by the presence of external perspectives and internal perspectives: the external interface perspectives (supplier, customer and EE) against the internal perspective.

\section{Insert figure 1 here}

The interaction of the EE Balanced Scorecard at each EE node - from company $\mathrm{x}$ to its suppliers and customers - is depicted in figure 2. Please note that the situation described by Bititci et al. (2003), i.e. the existence of more than one EE being serviced by any particular EE node is ignored for the sake of simplicity in figure 2; this situation would give rise to a series of complex PM interactions outside of the focal EE, and is beyond the scope of this paper. Each EE node is expected to apply the four perspectives of the scorecard - thus moving beyond measurement based upon 'traditional logistics measures' only - to enable an examination of both intra- and inter-organisational performance at each node. Each node is required to maintain their internal PM system as one perspective of the framework, while also up-keeping PM at the two 
surrounding interfaces - supplier and customer; finally the holistic approach is completely covered by reminding each node to account for certain EE measures in the EE-perspective.

\section{Insert figure 2 here}

Note the labels 'supplier interface PM system' and 'customer interface PM system' in figure 2; these represent the small system of measures that are held jointly between company $\mathrm{x}$ and each of its suppliers/customers - each supplier/customer requiring a separate interface system. In these interface systems, measures such as 'delivery time' measure much the same thing whether it is inbound delivery time (for company $\mathrm{x}$ from its suppliers, or from company $\mathrm{x}$ to its customers), or outbound delivery time (for suppliers to company $\mathrm{x}$, or company $\mathrm{x}$ to its customers) - the difference is often a matter of the viewpoint taken by the observer of the EE. Much of the raw data for these sorts of shared measures between succeeding EE nodes is found in the documentation that passes back and forth between them in the supplier-customer relationship (for example, Requests for Quotations, orders etc.); the position of the observer's focal company in the EE determines whether the selected measures belongs to the supplier or customer perspective of the EE Balanced Scorecard.

The internal perspective of figure 2 is dominated by the requirement to allow EE nodes develop their intra-organisational PM systems with a freedom of choice concerning internally-oriented PM frameworks of a structural nature. Since the compositional nature of the EE - comprising large-scale OEMs on one hand, and small-scale SMEs on the other - is highly varied, advocating a one-size-fits-all approach towards PM framework specification is unlikely to work. Further, as significant investment is likely to have been made in many companies in the EE in intraorganisational PM systems already, the EE PM system must attempt to incorporate these existing systems, or face a situation of non-usage owing to incompatibilities with the existing, inhouse, 
PM system. Each EE node, therefore, is free to use any structural framework for PM that it chooses when it begins the process of selecting measures based upon its strategy; this is subject to the proviso that the standardised performance measure template list (see research methodology) is used as the basis upon which performance at the internal perspective is monitored. This proviso allows individual nodes to express their independence at the intraorganisational level, while ensuring conformity to the standardised - EE wide - template list of measures; participation of the internal perspective of each EE node still remains despite the fact that different structural intra-organisational PM frameworks may be in use at various nodes of the EE.

The EE-perspective should consist of local (that is node-level) measures that must be aggregated up into EE level measures. The EE-perspective of the EE Balanced Scorecard represents, at each node of the EE, the EE PM system used by that node. The measures used represent measures held by a particular node that will ultimately be aggregated upon an EE level; measures are drawn and aggregated from the performance measure template list. The EE PM system may be seen as a series of node systems of measures that are combined to form the EE PM system; the more nodes an EE has, the larger the EE PM system may become, depending upon how many nodes wish to participate in the EE PM system. The methodology to perform this step requires co-ordination and information sharing, and is handled by the dashboard solution. The dashboard developed will provide a common platform to enable this information sharing and allow the linking of the respective EE perspectives at local-node level into an EE wide PM system, as depicted in the above figure. However, the dashboard will also support the other perspectives, in order to provide a complete picture of the EE at all node levels - whether from internal-, supplier-, customer- or EE-perspective level. 


\section{Extended Enterprise Procedural Framework}

The EE PM framework for the selection and implementation of measures is the procedural PM framework that provides the EE nodes with instructions for proceeding to distil their respective strategies into implementable measures for the internal-, supplier-, customer-, and EEperspectives of the EE Balanced Scorecard. Experiences from the automotive industry suggest that the procedural framework must have the ability to operate at two distinct levels; namely the holistic EE level, and the individual, EE node, level. It is for this reason that the procedural framework may be divided into two sections: the first section prescribes measures suitable for the supplier-, internal-, and customer-perspectives; and the second section prescribes aggregated measures for the EE-perspective. Essentially the first section concentrates upon developing a procedural PM framework for each EE node, without considering the EE in the holistic sense; the second section reinserts the EE-perspective into the discussion, to enable the development of the supplier-, internal-, and customer-based measures into aggregated EE-based measures. To facilitate the second section, the concept of an EE host must be introduced. The EE host is the member of the EE responsible for formulating, detailing and distributing information concerning the $\mathrm{EE}$ direction and requirements to the other nodes of the $\mathrm{EE}$; and for controlling the aggregated EE-perspective of the EE Balanced Scorecard. The recommended EE host is a firsttier supplier of the EE - a choice dictated by the need to avoid coercive practices in the EE from the introduction of a large-scale PM system that crosses a number of company boundaries. Lack of participation by EE nodes and failure of the initiative as a whole may result from the hijacking of the EE PM system by interested parties in the EE for their own direct needs; or by excessive PM politics that may complicate and weaken the implemented system. A first-tier supplier as EE host lies in an ideal position to counteract this: since they are suppliers to OEMs, and customers 
to second-tier suppliers, it is in their interest to see that the EE PM system can transcend the EE politics and technology differences found between OEMs and SMEs; plus the fact that they are also in a considerably weaker position - in terms of implementable political pressure - than an OEM, who, owing to their size and position, may inevitably try to manipulate the EE PM system for their own benefit only.

\subsection{Extended Enterprise node level procedural framework}

The procedural EE PM framework has relied heavily upon the intra-organisational procedural PM frameworks proposed by Bradley (1996) and Medori and Steeple (2000). It is depicted in figure 3 and detailed in a number of stages described below.

Insert figure 3 here

\section{Stage 1: Define the company's mission and strategy}

Depending upon the EE node's level of sophistication, this may be completed quickly. A series

of interviews and workshops amongst top-level management is how Kaplan and Norton (1993) propose that this stage should be handled. Unhelpful, vague and misleading statements in the resulting strategy should be avoided, and additional documentation - such as documents that help illuminate strategy - are also helpful.

\section{Stage 2: Derive the critical success factors and customer requirements from the company's strategy}

A PM axis should be used at this stage (see case study later). The axis combines the seven macro measures of performance from the performance measure template list on the vertical axes, with 
the internal-, supplier-, and customer-perspectives of the EE Balanced Scorecard on the horizontal axes, to accommodate 21 different types of success factor, each consisting of one macro measure of performance and one perspective. Critical success factors are identified from the derived strategy and added to the axis by:

- Determining the perspective - each statement in the mission and strategy statements is examined to discover whether the factor involved impacts upon our company alone, upon ourselves and our suppliers, or upon ourselves and our customers;

- Determining the macro measure of performance - how does each statement in the mission and strategy impact upon us? i.e. we determine if it affects us cost-wise, quality-wise etc.

This process is greatly facilitated by any additional documentation that may elucidate obscure statements in the strategy. Once the strategy and mission statements have been exhausted and the PM axis completed, the results may be converted into an adaptation of the Medori and Steeple (2000) PM grid.

\section{Stage 3: Select measures using performance measure template list}

Using the derived PM grid from stage 2 and the performance measure template list, the selection of the most suitable measures that conform to the EE KPI template list can be made. Using the 'macro measure of performance' and 'framework perspective' columns as a guide, measures matching (or closely matching) the critical success factors identified may be quickly located within the performance measure template list. It is likely that some of the critical success factors that have been identified may not have suitable measures applicable to it in the template list; in this case the performance measure template list requires auditing to ensure its currency. At the 
end of this section a list of measures for the internal-, supplier- and customer-perspective should have been specified under the various macro measures of performance. The supplier- and customer-perspective measures should be transmitted to the interested parties up- and downstream of the company in order that they may be taken into account in their strategy-formulation exercises; minor alterations and/or additional measures may come from either parties.

\section{Stage 4: Implementation of measures}

It is recommended that the Performance measure record sheet (Neely et al. 1997) is used at this stage (or an effective variant upon this). The use of the Performance measure record sheet in the dashboard helps to standardise the process of actually recording used measures in the EE; the standardisation of the layout of the sheet ensures that only relevant information is collected upon each measure. A standardised equation for calculation of each measure has been provided by the performance measure template list, so that calculations performed at each node of the EE remain constant.

\section{Stage 5: Periodic Review}

Each node of the EE will be expected to periodically review (the length of the periods between reviews is set by the EE host) the PM system put in place for the internal, supplier and customer perspectives. 


\subsection{Extended Enterprise level procedural framework}

The following procedural framework, being identical with the previously outlined framework upon many points, is only outlined briefly here. The stages in the process that the EE host should follow to develop an EE direction and requirements plan, reduce it to EE measures, and implement it is shown in figure 4.

\section{Insert figure 4 here}

In developing the EE direction and requirements plan, the EE host should develop the plan through an examination of the four factors of Waggoner et al. (1999): the internal, external, process and transformational issues of the EE should be understood in detail. The results of such a study should indicate the future impacts that may be perceivable upon the EE for all nodes of the EE. The O.E.M of the EE should also be able to provide a comprehensive overview of the requirements of the final customer of the EE; the expectations, needs and wants of the final customer are the driving force for the EE as a whole, and the EE plan should be formulated upon this. For stage 2 an adapted PM axis may be introduced: the adapted axis retains the macro measures of performance but changes the perspectives upon the horizontal axis to a number specifically developed for the EE arena; these are: material flow (e.g. no. of parts 'in' and 'out' of EE); information flow (e.g. orders, request for quotations up and down EE); control process's quality (quality of the planning processes involved in production planning and control in EE); inbound logistics; and outbound logistics. The process of identifying the critical success factors from the EE direction and requirements plan is performed in the same way as previously, whereupon the adapted PM axis is converted into a PM grid. At this stage, the selection of the most suitable unaggregated measures that conform to the performance measure template list can be made. In the derived PM grid, using the 'macro measure of performance' and 'framework 
perspective' columns as a guide, unaggregated measures matching (or closely matching) the critical success factors identified may be quickly located within the performance measure template list. Once unaggregated measures have been selected, the EE host must aggregate them in various combinations (see case study later), and transmit them to those parties that require them in the EE, using the dashboard. The EE host will be expected to periodically review the PM system put in place for the EE perspective.

\section{Case Study}

The identity of the company discussed in this case study, plus its associated EE partners, has been protected. The company is a first-tier supplier of chassis component products to leading automotive companies in the European automotive industry. Products are forged by the company to suit the requirements of three main customers, at seven separate locations in Europe; while the company has eleven suppliers, mainly based in Europe, that supply nineteen distinct components to the company. The company has its main manufacturing plant in Norway, and a duplicate plant in Canada to service their North American operations. This research is based upon collaboration with the Norwegian manufacturing plant, which is interested, as far as possible, in duplicating its European EE set-up in North America - hence its interest in EE PM. The following paragraphs examine the impacts of the procedural framework and EE Balanced Scorecard upon the company.

In 1999-2000, a number of ERP vendors were invited to tender proposals to the company; one result of the following consultation process was a complete picture of the company's mission and strategy, with a series of workshops between the ERP vendors and the company clarifying the 
'as-is' situation, and the desired 'to-be' situation. This developed mission and strategy was deemed to be suitable for PM development, and produced the PM axis and PM grid depicted in figure 5 .

\section{Insert figure 5 here}

Using figure 5 as a guide, table 2 was derived using the performance measure template list. These measures were subsequently implemented as the intra-organisational local node measure set, corresponding to the internal- and interface-perspectives (supplier and customer) of the EE Balanced Scorecard. The supplier- and customer-perspective measures were also made available, via the dashboard, to those parties in the EE that may have been affected by them. Note that there were three critical success factors for which it was deemed impossible to obtain suitable measures from the performance measure template list: flexibility of information flow; supply chain solutions; and plant location. These three critical success factors represent 'gaps' in the template list, which will subsequently have to be updated to account for these upon a regular basis.

\section{Insert Table 2 here}

The EE direction and requirements plan is an attempt on the part of the EE host to identify an EE strategy, or if that is not easily achievable, to at least identify the goals and visions of the EE, and the expected future outcomes which the EE may face. As the EE host in its respective EE, the company has the responsibility for developing the EE direction and requirements plan for its EE. Significant contributions to this plan are also made by the OEM. of the EE - in this case the leading European automotive companies - who are closest to the final customer. The company is fortunate in that they are part of the automotive industry, which is one of the most researched of industries; consequently, there exists a considerable amount of relevant information concerning the goals, visions and strategies adopted in the industry by OEMs and suppliers. This information 
is easily adaptable to the company's requirements. The company's EE direction and requirements plan is plotted in figure 6. The selection of the most suitable measures for the company's aggregation process may now be made.

\section{Insert figure 6 here}

Figure 7 illustrates the raw measures selected for the company: these measures are listed randomly, as they must be customised further into EE performance measures by the process of aggregation. A significant number of critical success factors could not be covered, because matching measures could not be located in the performance measure template list; in particular, critical success factors for Innovation and Environment categories were difficult to incorporate these areas represent relatively new areas for measure development, and may require further clarification before measures with sufficient coverage can be developed to suit them.

\section{Insert Figure 7 here}

Concerning aggregations of raw measures into EE measures: aggregations of measures may only take place between measures with the same macro measures of performance - for example, a time measure with a time measure, a cost measure with a cost measure etc. Mixed macro measures of performance (e.g. times and costs) are relatively impossible to measure adequately, and usually require one type to be transposed (in some way) into the other; flexibility, precision and environmental performance measures - for example - are difficult to aggregate as they may be comprised of different macro measures of performance. Here, the company are interested in different EE structures, comprising various supplier and customer formations, so various EE measures, based upon figure 7, can be developed depending upon the level of aggregation the company wish to achieve. For example, the company may measure 'EE information throughput time' by measuring the time taken for the ordering process at each node (single unaggregated value), at a number of nodes in the EE (an aggregated number of information throughput time 
measures from different nodes), or all the nodes in the EE (an aggregated number of information throughput time measures from all nodes); thus:

EE Information throughput time @ node 1=(Order receive time + Order process time $)$ node 1

or

EE Information throughput time @ nodes 1 and $4=($ Order receive time + Order process time) @ node $1+($ Order receive time + Order process time $) @$ node 4

or

EE Information throughput time @ all nodes $=($ Order receive time + Order process time $) @$ node $1+\ldots+($ Order receive time + Order process time $) @$ node $n$

Notice how 'EE information throughput time' is an EE measure developed by aggregating one or more measures from the list chosen in figure 7. Some EE measures require little aggregation, while others do; some of the most aggregated ones that may be developed by the company are illustrated in table 3 . This list often uses indirect aggregations to try and measure critical success factors that couldn't otherwise be measured; the list is not exhaustive as the possible aggregations of measures from figure 7 above, to form new EE measures, is very high; and at any time, the company may be interested in only some of these.

Insert Table 3 here

The EE measures developed by the company are transmitted to the responsible EE nodes via the Extranet dashboard. As the calculation of the EE measures is performed by the aggregation process, the company sends to each participating EE node only the unaggregated measures that will be required from them. In this way, only those nodes with responsibility for certain EE measures will be required to reply to the company with their measurements of these via the 
Extranet. Overall control and responsibility for the development, maintenance, and updating of EE measures rests with the company, although suggestions from other EE nodes may be taken from time to time. The company's completed EE Balanced scorecard may now be represented in figure 8.

Insert figure 8 here

\section{Discussion}

The above EE PM system relies upon two separate entities, working in combination, to become operational: the EE Balanced Scorecard offers a four-perspective framework - to be implemented at each EE node - that provides a generic structure for the management of performance measures in the EE; and the procedural framework operates at both the EE node and holistic EE levels to provide a step-by-step generic process towards the selection and implementation of measures. The complete system makes a number of assumptions, all of which result from the fusing of two diverse subjects; by attempting to combine the EE with PM we are, in effect, combining the practicalities and problems associated with the EE under the PM umbrella. The generic characteristics of the EE have been examined by a number of commentators (for example, O’Neill and Sackett (1994), Jagdev and Browne (1998), Browne and Zhang (1999), Jagdev and Thoben (2001)), and many of the issues first raised there can be seen to have a critical impact upon any PM system designed to suit the requirements of the EE paradigm. We therefore emphasise that the PM system described here is designed to work within the EE paradigm; issues of co-operation and trust, for example, in the EE are taken as essential starting-point assumptions. 
With the development of new concepts in the arena of PM, comes the requirement that the associated and larger arena of performance management is updated to reflect these developments; management both precedes and follows measurement, and in doing so creates the context for its existence (Lebas 1995). Bititci et al. (2003) state it is critical, in collaborative enterprise value systems, that the manage processes of individual organisations are co-ordinated to ensure the creation and sustentation of competitive advantage. To this end, the developed EE PM system requires legislation; the basic aim of which is the controlling of administrative issues surrounding the PM system in the EE. This is the responsibility of EE performance management, which, alongside the development of a standardised list of performance measures, must explicate standardised administrative policies to regulate the EE at the high EE level, and at the local, node level. Apart from the research of Bititci et al. (2003), who tackle the issue by proposing the need for a meta level performance management process to integrate and co-ordinate the individual performance management processes of each enterprise in the EE architecture, work in this area hardly exists; there is a need in future work for the exposition of a complete EE performance measurement/management system by either bottom up (i.e. beginning with PM as in this paper) or top-down (i.e. beginning with performance management as in Bititci et al. (2003)) techniques.

The company case study outlined above represents only a partial analysis of the EE PM system developed here; further case studies should be contemplated which actively examine the development of the EE PM system at multiple nodes in the EE and the interaction between these individual site PM systems with each other. On-going usage in a real-time EE is the only method that can effectively assess the long-term utility and conformity of the EE PM system. 


\section{Acknowledgments}

The research described in this paper was produced under the MOMENT project (GRD1-2001-

40488) - which was funded by the European Commission's program for Competitive and Sustainable Growth under the Fifth Framework program.

\section{Figure Captions}

Figure 1. Extended Enterprise Balanced Scorecard framework

Figure 2. Interaction of the Extended Enterprise Balanced Scorecard

Figure 3. Procedural Extended Enterprise performance measurement framework - local node

Figure 4. Procedural Extended Enterprise performance measurement framework - EE perspective

Figure 5. Company's performance measurement axis and performance measurement grid

Figure 6. Company's adapted performance measurement axis and performance measurement grid

Figure 7. Raw performance measures selected for EE measure development process

Figure 8. Company's EE Balanced Scorecard 


\section{Tables}

Table 1. Frameworks for inter-organisational performance measurement

\begin{tabular}{|c|c|c|c|}
\hline Framework & Researcher & $\begin{array}{c}\text { Framework } \\
\text { Typology }\end{array}$ & Dimensions of measurement (if any) \\
\hline $\begin{array}{l}\text { Beamon's } \\
\text { framework }\end{array}$ & (Beamon 1999) & Structural & Resources; Output; Flexibility \\
\hline $\begin{array}{l}\text { Supply Chain } \\
\text { Balanced Scorecard } \\
\text { framework }\end{array}$ & $\begin{array}{l}\text { (Brewer and } \\
\text { Speh 2000) }\end{array}$ & Structural & $\begin{array}{c}\text { Customer perspective; Internal } \\
\text { business perspective; Innovation and } \\
\text { learning perspective; Financial } \\
\text { perspective }\end{array}$ \\
\hline Lapide's framework & (Lapide 2000) & Structural & $\begin{array}{l}\text { Executive-level metrics; Managerial- } \\
\text { level metrics }\end{array}$ \\
\hline Dreyer's framework & (Dreyer 2000) & Procedural & - \\
\hline $\begin{array}{l}\text { Gunasekaran et al.'s } \\
\text { framework }\end{array}$ & $\begin{array}{l}\text { (Gunasekaran et } \\
\text { al. 2001) }\end{array}$ & Structural & $\begin{array}{l}\text { Plan performance; Source } \\
\text { performance; Production performance; } \\
\text { Delivery performance; Customer } \\
\text { service and satisfaction }\end{array}$ \\
\hline Six step framework & (Basu 2001) & Procedural & - \\
\hline $\begin{array}{c}\text { Integrated } \\
\text { measurement } \\
\text { system }\end{array}$ & $\begin{array}{l}\text { (Bullinger et al. } \\
\text { 2002) }\end{array}$ & Structural & $\begin{array}{l}\text { Financial perspective; Customer } \\
\text { perspective; Organisational } \\
\text { perspective; Innovation perspective; } \\
\text { Supply chain perspective; Process } \\
\text { perspective; Function perspective }\end{array}$ \\
\hline $\begin{array}{l}\text { Process-based } \\
\text { framework }\end{array}$ & $\begin{array}{c}\text { (Chan and Qi } \\
\text { 2003) }\end{array}$ & Structural & $\begin{array}{l}\text { Suppliers; Inbound logistics; Core } \\
\text { manufacturer; Outbound logistics; } \\
\text { Marketing and sales; End customers }\end{array}$ \\
\hline $\begin{array}{c}\text { Supply chain } \\
\text { performance } \\
\text { metrics framework }\end{array}$ & $\begin{array}{l}\text { (Gunasekaran et } \\
\text { al. 2004) }\end{array}$ & Structural & $\begin{array}{c}\text { Plan; Source; Make / Assemble; } \\
\text { Deliver; Strategic; Tactical; } \\
\text { Operational }\end{array}$ \\
\hline
\end{tabular}


Table 2. Measures for the internal-, supplier-, and customer-perspectives

\begin{tabular}{|c|c|c|}
\hline $\begin{array}{l}\text { Macro measure of } \\
\text { performance }\end{array}$ & Framework perspective & Performance Measure \\
\hline \multirow[t]{3}{*}{ Cost } & Internal & $\begin{array}{c}\text { Plant operational cost per hour } \\
\text { Process cost } \\
\text { Gross Profit }\end{array}$ \\
\hline & Supplier & Delivery cost \\
\hline & Customer & Delivery cost \\
\hline \multirow[t]{2}{*}{ Time } & Supplier & Delivery time \\
\hline & Customer & $\begin{array}{c}\text { Delivery time } \\
\text { Delivery frequency }\end{array}$ \\
\hline \multirow[t]{3}{*}{ Quality } & Internal & $\begin{array}{l}\text { Manufacturing quality } \\
\% \text { of products that fail test }\end{array}$ \\
\hline & Supplier & Warranty and returns \\
\hline & Customer & $\%$ of release errors \\
\hline Flexibility & Internal & $\begin{array}{c}\text { Manufacturing process } \\
\text { flexibility } \\
\end{array}$ \\
\hline \multirow[t]{3}{*}{ Precision } & Internal & Production plan adherence \\
\hline & Supplier & Delivery accuracy \\
\hline & Customer & Delivery accuracy \\
\hline Innovation & Customer & $\begin{array}{c}\text { Identify market requirements } \\
\text { time }\end{array}$ \\
\hline
\end{tabular}


Table 3. Some EE measures with high aggregation

\begin{tabular}{|c|c|}
\hline EE measure name & Aggregated Formula \\
\hline $\begin{array}{l}\text { EE Inventory level cost @ } \\
\text { all nodes }\end{array}$ & $\begin{array}{l}\text { (Inventory carrying cost) @ node } 1+\ldots+\text { (Inventory carrying } \\
\text { cost) @ node n }\end{array}$ \\
\hline $\begin{array}{l}\text { Cost of new core } \\
\text { competencies @ node } 1\end{array}$ & $\begin{array}{c}\text { (Process cost + Product research cost + Material cost + Package } \\
\text { cost + R\&D depart. cost + Manuf. depart. cost) @ node } 1\end{array}$ \\
\hline $\begin{array}{l}\text { Cost reduction via asset } \\
\text { elimination / mergers @ } \\
\text { node } 1\end{array}$ & $\begin{array}{c}\text { Original }(\mathrm{A})-\mathrm{New}(\mathrm{A}) \\
\text { Where } \mathrm{A}=\text { Process cost }+ \text { Product research cost }+ \text { Material cost }+ \\
\text { Package cost }+ \text { R\&D depart. cost }+ \text { Manuf. depart. cost }+ \text { Delivery } \\
\text { costs etc. }\end{array}$ \\
\hline $\begin{array}{l}\text { EE Delivery performance @ } \\
\text { all nodes }\end{array}$ & $\begin{array}{c}\text { (No. of on-time deliveries) / (Total deliveries made ) @ node } 1+ \\
\ldots+(\text { No. of on-time deliveries) / (Total deliveries made ) @ node } \\
n\end{array}$ \\
\hline EE Market share & $\begin{array}{l}\text { Last years customers + No. of newly acquired customers this year } \\
\qquad / \text { all customers in market }\end{array}$ \\
\hline EE level of collaboration & $\begin{array}{l}\text { Average product development lead time @ node } 1+\ldots+\text { Average } \\
\text { product development lead time @ node n }\end{array}$ \\
\hline EE delivery time & $\begin{array}{c}\text { Delivery time to OEM from company - Delivery time from node } \\
\mathrm{n} \\
\text { Where } \mathrm{n}=\text { lowest positioned node in the supply chain }\end{array}$ \\
\hline EE planning process quality & No. of plan variations per year @ company (as EE host) \\
\hline $\begin{array}{l}\text { No. of potential core } \\
\text { competencies@ node } 1\end{array}$ & $\begin{array}{c}\text { [[(Manufacturing process flexibility })+(\text { Source flexibility })] \text { of } \\
\text { actual production }+[(\text { Manufacturing process flexibility })+(\text { Source } \\
\text { flexibility })] \text { of potential production })] @ \text { node } 1\end{array}$ \\
\hline EE Forecast precision & [(Actual Forecast result) @ OEM - (Forecasted Result) @ OEM] \\
\hline Call-off precision @ node 1 & $\begin{array}{c}{[(\% \text { of release errors })+(\% \text { of invoices released with errors })+} \\
\text { other call-off errors }] / \text { No. of Call-offs }] @ \text { node } 1\end{array}$ \\
\hline
\end{tabular}




\section{References}

BASU, R., 2001, New criteria of performance management: a transition from enterprise to collaborative supply chain. Measuring Business Excellence, 5 (4), 7-12.

BEAMON, B. M., 1998, Supply chain design and analysis: models and methods. International Journal of Production Economics, 55, 281-294.

BEAMON, B. M., 1999, Measuring supply chain performance. International Journal of Operations \& Production Management, 19 (3), 275-292.

BITITCI, U. S., MARTINEZ, V., ALBORES, P. and MENDIBIL, K., 2003, Creating and sustaining competitive advantage in collaborative systems: the what and the how. Production Planning and Control, 14 (5), 410-424.

BLACKHOUSE, C. and BURNS, N., 1999, Agile value chains for manufacturing - implications for performance measures. International Journal of Agile Management Systems, 1 (2), 76-82. BRADLEY, P., 1996, A performance measurement approach to the re-engineering of manufacturing enterprises. PhD Thesis, CIMRU, NUI Galway, Ireland.

BREWER, P. and SPEH, T., 2000, Using the balanced scorecard to measure supply chain performance. Journal of Business Logistics, 21 (1), 75-93.

BROWNE, J., SACKETT, P. and WORTMANN, J. C., 1995, Future manufacturing systems towards the extended enterprise. Computers in Industry, 25, 235-254.

BROWNE, J. and ZHANG, J., 1999, Extended and virtual enterprises - similarities and differences. International Journal of Agile Management Systems, 1 (1), 30-36.

BULLINGER, H. J., KUHNER, M. and VAN HOOF, A., 2002, Analysing supply chain performance using a balanced measurement method. International Journal of Production Research, 40 (15), 3533-3543. 
CHAN, F. and QI, H., 2003, Feasibility of performance measurement system for supply chain: a process-based approach and measures. Integrated Manufacturing Systems, 14 (3), 179-190.

DREYER, D., 2000, Performance measurement: a practitioner's perspective. Supply Chain Management Review, September-October, 62-68.

GUNASEKARAN, A., PATEL, C. and MCGAUGHEY, R. E., 2004, A framework for supply chain performance measurement. International Journal of Production Economics, 87 (3), 333 347.

GUNASEKARAN, A., PATEL, C. and TIRTIROGLU, E., 2001, Performance measures and metrics in a supply chain environment. International Journal of Operations \& Production Management, 21 (1/2), 71-87.

HOLMBERG, S., 2000, A systems perspective on supply chain measurements. International Journal of Physical Distribution \& Logistics, 30 (10), 847-868.

JAGDEV, H. and BROWNE, J., 1998, The extended enterprise - a context for manufacturing. Production Planning and Control, 9 (3), 216-229.

JAGDEV, H. and THOBEN, K., 2001, Anatomy of enterprise collaborations. Production Planning and Control, 12 (3), 437-451.

KAPLAN, R. and NORTON, D., 1993, Putting the balanced scorecard to work. Harvard Business Review, September-October, 134-147.

KAPLAN, R. S. and NORTON, D., P., 1992, The balanced scorecard - measures that drive performance. Harvard Business Review, January-February, 71-79.

KLEIJNEN, J. and SMITS, M., 2003, Performance metrics in supply chain management. Journal of the Operational Research Society, 54 (5), 507-514.

LAPIDE, L., 2000, True measures of supply chain performance. Supply Chain Management Review, July-August, 25-28. 
LEBAS, M., 1995, Performance measurement and performance management. International Journal of Production Economics, 41 (1-3), 23-25.

MEDORI, D. and STEEPLE, D., 2000, A framework for auditing and enhancing performance measurement systems. International Journal of Operations \& Production Management, 20 (5), $520-533$.

NEELY, A., RICHARDS, H., MILLS, J., PLATTS, K., and BOURNE, M., 1997, Designing performance measures: a structured approach. International Journal of Operations \& Production Management, 17 (11), 1131-1152.

O' NEILL, H. and SACKETT, P., 1994, The extended manufacturing enterprise paradigm. Management Decision, 32 (8), 42-49.

ROUSE, P. and PUTTERILL, M., 2003, An integral framework for performance measurement. Management Decision, 41 (8), 791-805.

WAGGONER, D., NEELY, A. and KENNERLEY, M., 1999, The forces that shape organisational performance measurement systems: an interdisciplinary review. International Journal of Production Economics, 60-61, 53-60. 